\title{
HUKOU E MIGRAÇÃO NA CHINA: ALGUNS APONTAMENTOS SOBRE DIVISÃO DO TRABALHO*
}

\section{Paula Nabuco ${ }^{a}$}

RESUMO: O principal objetivo deste artigo é analisar as novas condições de trabalho na China e sua importância para o recente desenvolvimento econômico do país. Para tanto, nos concentramos nas relações e condições de trabalho dos trabalhadores migrantes do país, que constituem a maioria da força de trabalho empregada nas empresas com fundos externos, assim como nas companhias privadas que atuam no leste e sudoeste do país. Nossa proposta é mostrar, ao menos parcialmente, como as mudanças recentes e a divisão do trabalho histórica entre campo e cidade na China geraram as condições singulares da força de trabalho do país. A reforma agrária e o sistema de registro de residência (chamado hukou em chinês) juntamente com o grande volume de investimentos feitos depois do início das reformas geraram o maior fluxo migratório interno que o mundo já viu.

PALAVRAS-CHAVE: China; trabalho; migração; divisão do trabalho.

CLASSIFICAÇÃO JEL: J010; J100.

\footnotetext{
* Artigo recebido em 20/05/2012 e aprovado em 22/08/2012.

a Pós-doutoranda Universidade Federal do Espírito Santo e bolsista Capes. Contato: pnabuco@bol.com.br.
} 


\title{
THE HUKOU SYSTEM AND MIGRATION IN CHINA: SOME NOTES ON THE DIVISION OF LABOUR
}

\begin{abstract}
The main purpose of this paper is to analyze the new labour conditions in China and its importance on the countryís recent economic development. For that matter we focus on the labour conditions and labour relations of the migrant workers, who are the majority of the labour force employed by the foreign funded enterprises in China, as well as by the private companies working on the east and southeast regions of China. We aim at showing, at least partially, how the recent changes and the countryís historical division between the urban and rural areas shaped some of the unique conditions of Chinese labor force. The land reform and the household registration system (called hukou in Chinese), along with the huge amount of investments made after the adoption of the reforms, produced the biggest internal migration flux that the world has ever seen.
\end{abstract}

KEYWORDS: China; labor; migration; labor division. 


\section{INTRODUÇÃO}

As elevadas taxas de crescimento do produto interno bruto chinês, bem como de sua produção industrial, da população empregada pelo setor no país e sua estrutura de custos, têm alimentado um intenso debate a respeito da desindustrialização ao redor do mundo promovida pelo crescimento econômico chinês. Países como México, Brasil e Estados Unidos, a despeito da diversidade de suas estruturas econômicas, enfrentam, em maior ou menor grau, problemas gerados pela elevada competitividade dos produtos chineses e seus efeitos sobre sua indústria e geração de empregos.

As explicações mais comuns sobre o fenômeno chinês e seus efeitos sobre o mundo têm se limitado a analisar a situação chinesa segundo algum tipo de "algoritmo" que supostamente poderia oferecer a chave de leitura para o que ocorre no gigante asiático. Assim sendo, a capacidade desses países de gerar políticas que possam lidar adequadamente com a "ameaça" que a China representaria para suas economias tem sido, em muitos casos, insuficiente. Isso não significa afirmar, no entanto, que o câmbio artificialmente desvalorizado da China ou os baixos salários pagos aos trabalhadores do país, para citar algumas das explicações mais correntes, não sejam verdadeiras ou mesmo parte importante da análise a respeito do acelerado desenvolvimento da China.

O problema é que, sem uma consideração mais precisa da realidade e dos determinantes internos que possibilitam essa competitividade, não é possível apreender as peculiaridades do país asiático, em que medida elas são mais ou menos significativas e nem prescrever políticas adequadas para lidar com a nova divisão internacional do trabalho, que tem na China um dos seus grandes protagonistas.

Uma análise com a abrangência e profundidade adequadas, no entanto, escapa ao escopo deste artigo, dada a profundidade e a dificuldade impostas por um estudo com esse objetivo. O que este trabalho busca fazer é dar uma contribuição aos estudos sobre as mudanças ocorridas na estrutura das relações de trabalho na China, o crescimento da importância relativa de seu setor industrial na geração de empregos tanto internamente, quanto em termos do total de empregos do setor no mundo, a partir das condições de trabalho e renda de um dos grupos mais importantes no que se refere à oferta de trabalho na China: os trabalhadores migrantes.

Desde a adoção da política de reforma e abertura e, mais significativamente, a partir do início da década de 1990 a China viveu uma explosão migratória. O aumento do volume de investimentos externos diretos, a crescente demanda por força de trabalho nas regiões leste e sul, a ampliação da diferença de renda campo-cidade e a escassez relativa de terras provocaram a expulsão de grandes contingentes de força de trabalho do campo (especialmente do centro do país) em direção ao oriente e sul, mais ricos e 
receptores da maior parte dos recursos e novos postos de trabalho. As condições de vida e de trabalho dos migrantes, bem como suas transformações mais recentes podem ajudar a compreender melhor a China contemporânea.

Em 1958, o país asiático aprovou o estabelecimento de um sistema de registro de residência (chamado hukou em chinês). De acordo com ele, os chineses possuiriam um registro segundo local de nascimento e, portanto, de residência, que poderia ser urbano ou rural, e uma classificação por relação de trabalho, agrícola ou não agrícola. Até o início da década de 1980, esse sistema e seus mecanismos eram parte da política de "industrialização sem urbanização" do país, nos termos usados pelo próprio Mao Zedong ${ }^{1}$. Depois disso, com a crescente demanda por força de trabalho, os mecanismos de controle foram relaxados em maior ou menor grau, dependendo do período tratado e da região.

Esses trabalhadores migrantes constituem hoje a força motriz do setor mais dinâmico da indústria chinesa - o das empresas privadas que operam nas regiões leste e sul - com longas jornadas de trabalho e salários relativamente baixos. Essa regiões e as grandes cidades recebem milhões de trabalhadores migrantes a cada ano, sob condições muito específicas. As diferenças nas condições de vida do campo e da cidade que geraram essa oferta de trabalho e o papel da reforma agrária no estabelecimento do atual nível de competitividade do país asiático são alguns dos elementos analisados neste artigo.

\section{AS DIFERENÇAS ENTRE CAMPO E CIDADE}

Segundo dados do Departamento Nacional de Estatísticas (DNE) da China, o índice de Gini, indicador usado para avaliar a distribuição de renda, aumentou de aproximadamente 0,3 no início da década de 1980 para acima de linha de alarme de 0,4 em 2000. Em 2010 o índice atingiu 0,48 segundo dados do DNE. Apesar da crescente resistência dos trabalhadores migrantes aos baixos salários, a dependência da renda obtida por esses trabalhadores nas cidades costeiras da China é significativa.

A diferença de renda entre os trabalhadores urbanos e rurais do país aumentou nos últimos anos. A renda per capita disponível dos residentes urbanos em 2009 foi de 17.175 yuans, o que representa uma alta anual de $8,8 \%$, segundo dados divulgados pelo diretor do Departamento de Estatísticas chinês, Ma Jiatang. (Agência de Notícias Xinhua, 22/01/2010) Segundo ele, no caso dos residentes rurais a renda foi de 5.153 yuans, com uma taxa de crescimento registrada de $8,2 \%$, taxa inferior a dos residentes urbanos. A proporção entre a renda urbana e rural foi de 3,33 para 1, em 2008. Em

\footnotetext{
${ }^{1}$ O nome do líder chinês, mais conhecido no Brasil como Mao Tsé-Tung, assim como todos os termos em chinês neste artigo estão grafados segundo o sistema para romanização do chinês, Pin Yin, adotado pela República Popular da China em 1979.
} 
agosto de 2012, o governo chinês publicou um novo estudo, o Livro Azul Urbano: Relatório Número 5 do Desenvolvimento Urbano da China, editado pela Academia Chinesa de Ciências Sociais (CASS, 2012). Segundo ele a renda urbana chinesa representa hoje 5,2 vezes a das áreas rurais, um aumento de $86 \%$ em relação a 1986 . Ademais, a atualização dos dados do último censo populacional (de 2010) mostra que o percentual de moradores urbanos ultrapassou o de residentes rurais, com 51,27\% dos chineses vivendo em cidades.

Atualmente a renda dos trabalhadores migrantes que trabalham fora de sua terra natal corresponde a $40 \%$ da renda disponível per capita de suas famílias no campo. Os rendimentos obtidos com a venda de produtos agrícolas correspondem a 49\% da renda. Segundo o economista chinês Hu Angang, a diferença de renda entre o campo e a cidade se tornou um grave problema para o avanço do desenvolvimento chinês (Agência de Notícias Xinhua, 22/01/2010). Ademais, considerando a dependência de parte significativa da renda familiar dos ganhos obtidos por seus membros migrantes nas grandes cidades, fica claro que, apesar da crescente resistência dos trabalhadores às difíceis condições de trabalho nas cidades, eles ainda devem continuar migrando em busca dos salários mais altos nas indústrias do leste e sul do país, pelo menos no curto prazo.

Em 1983, o "Regulamentos Relacionados com a Cooperação entre Cidades e Vilas" que funcionava como espécie de autorização para a migração rumo aos mercados das cidades sob a condição de que os migrantes levassem consigo suas cotas de alimentos, marcou o adensamento dos fluxos migratórios. Desde então, a melhoria na produtividade no interior fez com que a produção requeresse menos trabalhadores, mas, ao mesmo tempo, por conta de diversas dificuldades (falta de implementos agrícolas, elevada densidade demográfica, etc.), as parcelas de terra também se tornaram menos lucrativas. $\mathrm{O}$ estímulo à migração passou a ser considerado, pelos governos locais, uma forma de gerar ampliação na renda local. Mais que isso, eles passaram a fazer um discurso sobre uma suposta cooperação com outras regiões. "Nós consideramos o trabalho migrante uma forma de cooperação entre as partes leste e oeste do país", disse o secretário do Partido Comunista da província de Sichuan, Xie Shijie, que completou: "Eles saem daqui de mãos vazias e retornam ricos - é como fazer dinheiro do nada" (Harney, 2009, p. 112).

Os migrantes passaram a cumprir um papel fundamental na transferência de renda para o campo desde o início do processo de reforma e abertura. Em muitas regiões do interior do país eles são chamados de "fábricas sem fumaça". Com isso, as províncias fornecedoras passaram a cumprir um papel importante "empurrando" os camponeses para as cidades e províncias mais prósperas. $\mathrm{O}$ trabalho migrante e a renda que os camponeses migrados enviavam para suas províncias de origem representaram $16 \%$ do 
crescimento do produto interno bruto (PIB) chinês entre 1987 e 2005. Segundo Harney (2009), os moradores de um vilarejo em Sichuan recebiam em remessas pelo correio o equivalente a cinco vezes a arrecadação do governo local.

Com o tempo, a migração se tornou um negócio organizado pelos governos provinciais e pequenos vilarejos. Seus departamentos de trabalho passaram a organizar grupos de migrantes e agenciá-los na construção civil, em fábricas ou como empregados domésticos nas províncias de destino. Algumas províncias estabeleceram escritórios nas províncias receptoras para organizar com mais acuidade o agenciamento da força de trabalho que enviariam. Em 1993, a Agência de Notícias Xinhua afirmava que a maioria dos governos locais estava adotando políticas para encorajar a migração dos camponeses. Segundo Solinger (1999), em outro caso relatado, na localidade de Miyun, perto de Beijing, o comitê local do partido encorajava cada residência ou família a enviar pelo menos um de seus membros ao trabalho nas cidades. O departamento de trabalho de Wuhan, uma cidade receptora de grandes contingentes de trabalhadores migrantes, publicou um documento no qual declarava que a "base para o recrutamento de equipes de construção civil é: se eles ainda não tiverem trabalhado para a unidade no passado, então eles devem ser amigos e parentes dos quadros e funcionários das firmas" (Solinger, 1999, p. 181).

Os mecanismos criados pela relação entre os governos das províncias acabaram por se tornar rapidamente uma das formas mais simples para que os trabalhadores migrassem com algum tipo de garantia de emprego na chegada. Com o crescimento deste sistema, depósitos passaram a ser exigidos dos trabalhadores que migravam como garantia. Mais uma forma para que as províncias de origem obtivessem fundos. Esse mecanismo teve fases de maior ou menor relevância, mas ainda funciona em diversas localidades.

\section{DIVISÃO DO TRABALHO, HUKOU E GÊNERO}

$\mathrm{Na}$ primeira década das reformas, o fluxo de migrantes era majoritariamente masculino e se dirigia prioritariamente para o setor de construção civil, que contava com muitos postos de trabalho e cujas exigências para contratação eram bastante baixas. Isso mudaria acentuadamente nas duas décadas posteriores de reforma e abertura, não só porque as mulheres passariam a representar parte significativa do fluxo migratório chinês, mas também porque uma nova divisão do trabalho acabaria por se estabelecer. Ela seria moldada por uma série de fatores como o ingresso de capital em novos setores econômicos depois da primeira fase de reforma e abertura, a necessidade de especialização do trabalho para obtenção de ganhos crescentes de produtividade requeridos pelo capital, a ampliação do papel da China na própria divisão internacional do trabalho e sua 
nova condição de "chão de fábrica do mundo", e o rápido crescimento do setor industrial vivido pelo país na década de 1990, combinado com um encolhimento da participação das empresas estatais.

Esta seção analisa a divisão do trabalho no setor mais dinâmico da economia chinesa ao longo da segunda fase das reformas, a indústria e a divisão do trabalho no setor, na costa e no sul da China, onde se concentram os grandes investimentos externos. A força de trabalho crescentemente demandada para alimentar esse processo é, na sua maioria esmagadora, migrante. Ao longo do período entre 1990 e 2000, a indústria chinesa registrou crescimento no volume de pessoal ocupado, no valor adicionado industrial e na produtividade do trabalho. Na década seguinte, entre 2000 e 2010, a indústria continuou incorporando mais e mais força de trabalho, mas os incrementos de produtividade não foram tão significativos quanto na década anterior, segundo compilação de dados dos anuários estatísticos chineses de diversos anos.

A força de trabalho chinesa em 2009 era de cerca de 790 milhões de pessoas, 58\% da população do país (National Bureau of Statistics of China, 2010). De acordo com dados da Organização Mundial do Trabalho (OIT), citados por Gao, a força de trabalho chinesa representa $24,6 \%$ da força de trabalho mundial. Segundo Gao (2011), a força de trabalho industrial da China ultrapassou a dos países da Organização para a Cooperação e Desenvolvimento Econômico (OCDE) em 1986 e atingiu 30\% do total mundial, a primeira apresentava uma trajetória ascendente na composição da força de trabalho industrial, a segunda passou por uma redução sistemática de seu

Gráfico 1 - China: composição da força de trabalho por setor, 1990-2008

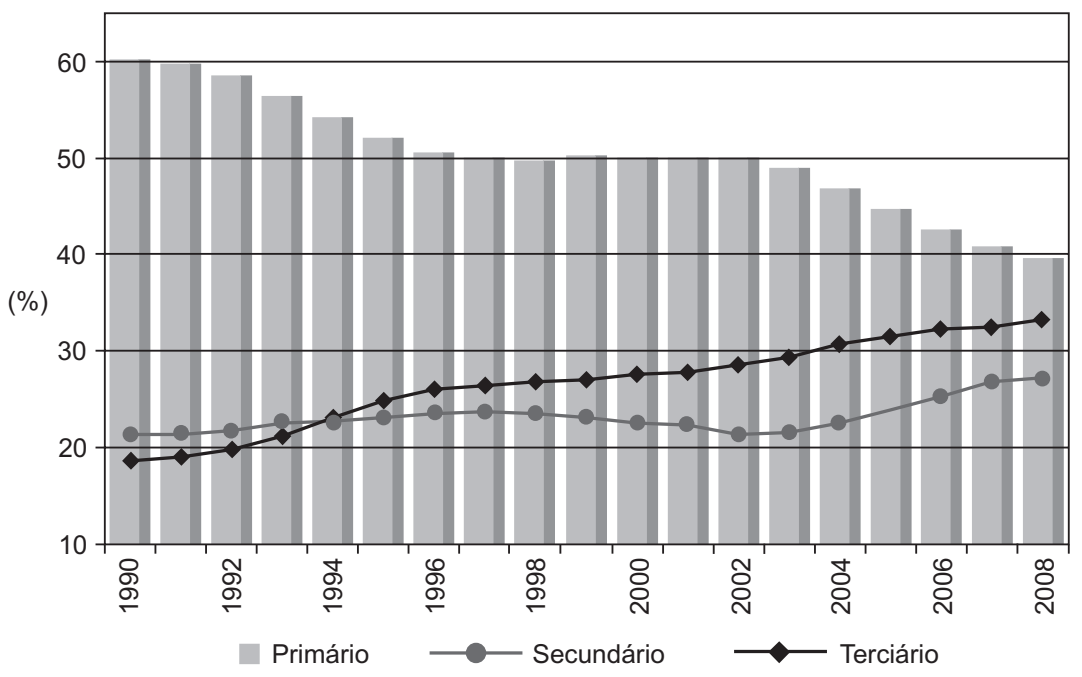

Fonte: National Bureau of Statistics of China (2010). 
contingente desde então. Já a China em 1980 contava com cerca de $23 \%$ e atingiu aproximadamente $32 \%$ em 2007.

Em 2010 a força de trabalho empregada no setor industrial chinês era de 216,48 milhões de pessoas, $27,8 \%$ do total da população economicamente ativa, segundo dados do governo chinês (National Bureau of Statistics of China, 2010). De acordo com Chan (2010), a China tem hoje pelo menos 150 milhões de trabalhadores migrantes, sem contar aqueles empregados nas Town and Village Enterprises (TVEs), em pequenas cidades e vilarejos perto de suas residências originais. Incluindo também esses trabalhadores o número de migrantes chineses chegaria a (pelo menos) 220 milhões em 2008. Considerando que $82 \%$ destes trabalhadores migram para as províncias que concentram os investimentos externos, podemos estimar que este contingente seja de aproximadamente 130 milhões de trabalhadores ${ }^{2}$. Eles atuam tanto em empresas de investimento privado, quanto em TVEs (ainda que elas também contem com investimento privado, têm características distintas).

A província de Guangdong, o grande laboratório das reformas, conta com aproximadamente 110 milhões de habitantes, com pelo menos 400.000 fábricas e três Zonas Econômicas Especiais. Do total de força de trabalho local, a maioria é feminina e migrante (Harney, 2009). Atualmente essas trabalhadoras correspondem a cerca de $60 \%$ do total de trabalhadores migrantes na China. É muito difícil estimar qual a participação dos trabalhadores migrantes no total da força de trabalho industrial chinesa, mas certamente não é pequena, especialmente considerando o imenso recuo das estatais, principais empregadoras da força de trabalho industrial com hukou urbano, no total do emprego nas principais cidades chinesas. Ademais, o deslocamento geográfico da indústria de base chinesa (do nordeste para o sul) faz com que a participação dos trabalhadores migrantes no total seja ainda mais expressiva, já que são eles a maioria da população e da força de trabalho nas cidades industriais do sul da China, especialmente em Guangdong. Não é exagero afirmar que a China só abriga a maior força de trabalho industrial do mundo hoje porque, além de ter a maior população mundial, também viveu o maior fluxo de migração interna da história, promovendo um grande êxodo de camponeses do interior do país.

A extração de sobretrabalho e a acumulação chinesas fizeram uma espécie de trânsito ao longo do processo de reforma e abertura, a modernização chinesa, termo usado pelos dirigentes do país para se referir aos esforços de industrialização no país, promoveu o estabelecimento de novas relações entre campo e cidade no país. Seu eixo central deixou de ser a extração dos camponeses no campo e passou a se concentrar nos

\footnotetext{
${ }^{2}$ Em nossa estimativa consideramos o total de migrantes em 2008 de 150 milhões, apesar dos problemas de cálculo já indicados anteriormente. Excluímos os trabalhadores que Chan (2010) afirma que atuam em TVEs perto de suas vilarejos ou vilas de origem.
} 
camponeses (compelidos a migrar) nas cidades, onde foi potencializada pelo volume crescente de trabalho morto e diversas técnicas aplicadas para a extração de cada vez mais trabalho vivo no país. Os camponeses que migram não só são alijados da estrutura de benefícios sociais das cidades, como também da própria vida cotidiana nesses lugares, tanto por causa das restrições à sua circulação, pela falta de documentos (cujo caso típico são os "três sem"3), como também pela própria lógica de funcionamento das fábricas onde eles se empregam.

O expressivo crescimento econômico chinês e sua nova condição na divisão internacional do trabalho estão diretamente relacionados com o trabalho migrante barato, vindo das áreas rurais. Porém, a sua forma mais barata e (supostamente) submetida é o trabalho feminino, preferido em diversos setores da indústria chinesa, nas zonas de processamento. Mas essa ideia hegemônica a respeito das dagongmei ${ }^{4}$ como um corpo social submisso, obediente e facilmente "administrado" mostra todas as suas contradições nas lutas e enfretamentos do cotidiano.

Segundo Andor, citado por Ngai (2007), em 1988 mais de 70\% da força de trabalho empregada na Zona Econômica Especial (ZEE) de Shenzhen era feminina, as dagongmei. Ainda de acordo com Ngai, 90\% da força de trabalho na manufatura leve em 1989 na ZEE era composta por trabalhadoras com menos de 25 anos. Um estudo da própria Ngai de 1990 (apud Ngai, 2007) mostrou que 95\% das mulheres trabalhadoras tinham a classificação de temporárias. Elas são maioria nas linhas de montagem e uma constante "dor de cabeça administrativa" para seus chefes na linha de produção, que geralmente são homens. Nenhum deles, aliás, conta com submissão voluntária das trabalhadoras. As reclamações sobre a disciplina são constantes e um dos métodos empregados é a comparação de gênero.

É raríssimo uma mulher sair da linha de produção e exercer cargo de chefia; normalmente elas se tornam no máximo supervisoras de linha. As linhas são normalmente compostas por trabalhadoras da mesma etnia ou província de origem, que também compartilham o mesmo quarto no dormitório da fábrica. A primeira pergunta feita no local de trabalho a uma trabalhadora recém chegada é sobre sua província de origem. Entretanto, essa pergunta feita em chinês tem um significado maior do que simplesmente de onde é a pessoa. Ela serve para indagar, ao mesmo tempo, qual a origem geográfica e étnica da trabalhadora. As trabalhadoras são sempre nomeadas segundo sua província de origem, pessoa de Sichuan, pessoa de Hunan e etc. Essas diferenças são usadas pela fábrica para reforçar a estrutura hierárquica e a própria divisão do trabalho.

\footnotetext{
${ }^{3}$ Esse é o termo usado para descrever os migrantes sem os documentos necessários para regularizar sua permanência nas cidades.

${ }^{4}$ Nome usado para se referir às trabalhadoras migrantes.
} 
A escolha do supervisor de linha é sempre feita levando em consideração seus vínculos étnicos, o prestígio e as boas relações com os trabalhadores. Mesmo quando as trabalhadoras são da mesma província elas são divididas segundo os dialetos locais. Os trabalhadores de Guangdong, uma província que tem diversos diletos locais, costumam ser divididos de acordo com a língua em grupos que falam cantonês, dialeto Chaozhou, ou Hakka. A divisão da força de trabalho segundo esses critérios reforça as diferenças entre os chineses provenientes das diferentes províncias, inclusive no que refere à hierarquia nos postos de trabalho na linha de produção. Pessoal de Hong Kong ou das grandes cidades chinesas, como Beijing, quando no sul, são parte do pessoal técnico ou especializado e ocupam cargos de chefia. Aqueles capazes de falar cantonês (que é a língua predominante em Hong Kong) falam a língua da chefia e têm status diferenciado. Todas essas divisões facilitam muito o controle sobre a força de trabalho nas grandes fábricas da costa chinesa.

As mulheres costumam ser preferidas nas linhas de montagem, especialmente da indústria eletrônica, porque são consideradas mais cordatas e fáceis de lidar - mas também por características físicas. Os dedos mais finos são considerados melhores no trato com os pequenos e sensíveis componentes da linha de montagem. Elas também são consideradas mais cuidadosas e ágeis na montagem dos componentes.

Como será discutido mais adiante na seção sobre a segunda geração migrantes, além da força de trabalho migrante ser cada vez mais feminina, ela também é cada vez mais jovem. É muito comum que jovens chinesas falsifiquem documentos para conseguir empregos nas cidades mesmo sendo menores de idade, e as fábricas e órgãos governamentais, apesar de saberem que isso acontece de forma sistemática, fingem não tomar conhecimento. As mais jovens chegam para trabalhar nas grandes cidades chinesas hoje com 16 ou 17 anos, e a média etária das trabalhadoras vem caindo de forma sistemática.

\section{a. DESEMPREGO}

Diversas pesquisas apontam que algo entre $70 \%$ e $80 \%$ dos trabalhadores migrantes conseguiam empregos em suas cidades de destino via parentes ou membros do mesmo vilarejo, algumas vezes antes mesmo de deixarem suas casas, ao longo da década de 1990 (Xin, 2004). Segundo Solinger (1999), no mesmo período, cinco pesquisas constataram que menos de $10 \%$ dos trabalhadores migrantes não obtinham empregos nas cidades em um curto período de tempo. Uma das pesquisas, feita em Guangdong, indicava que apenas $10 \%$ dos trabalhadores migrantes não conseguiam emprego depois de uma semana, e esse dado foi corroborado pelo departamento de trabalho local. Em Shanghai, cerca de 35\% dos migrantes já chegavam na cidade com um emprego assegurado e $74 \%$ dos migrantes começaram a trabalhar imediatamente. Outra pesquisa 
citada por Xin (2004) indica que na mesma época um levantamento feito em três cidades receptoras de migrantes (Shanghai, Dongguan e Jinan) constatou que a taxa de desemprego era de $2 \%$ entre os trabalhadores migrantes e que eles se concentravam em atividades consideradas inferiores pelos moradores urbanos.

Apesar das reclamações de muitos moradores urbanos sobre a potencial concorrência dos trabalhadores migrantes por empregos nas cidades, isso não se verifica. Algumas cidades adotaram medidas para tentar resguardar empregos para os moradores urbanos. Em 1997, a cidade de Nanjing demitiu 4.000 trabalhadores migrantes para abrir postos de trabalho para moradores urbanos. Das vagas abertas apenas 1.000 foram ocupadas por trabalhadores urbanos e muitos deixaram o emprego depois de alguns meses. Pouco tempo depois, a cidade precisou recontratar os trabalhadores migrantes (Tang e Yang, 2008).

No caso dos trabalhadores urbanos, o processo de privatização e desmantelamento das empresas estatais gerou um fenômeno novo, o desemprego, que passou a ser crescente a partir de meados da década de 1990, que foi marcada por um intenso processo de privatização. Os dados oficiais sobre os desempregados e demitidos das empresas vendidas ou fechadas são demasiadamente baixos considerando a profundidade das transformações sofridas pelas empresas estatais. Esse processo gerou uma legião de desempregados nas cidades chinesas, especialmente no nordeste do país.

As informações sobre o desemprego, não por acaso, são divergentes e problemáticas, especialmente por conta do método de coleta dos dados usado pelo governo chinês. De acordo com dados das Nações Unidas, em 1999, havia de 15,4 a 16,4 milhões de desempregados na China, uma taxa que variava de 7,9\% e 8,5\%. Um acadêmico chinês, Hong Lee, usando dados do governo chinês para “desempregados registrados" e de "demitidos", concluiu que o número de desempregados no mesmo ano no país era de 19, 5 milhões (Solinger, 2001).

O que pode ser afirmado com maior confiança é que, do contingente de desempregados na China, a maioria era de trabalhadores com hukou urbanos. Enquanto as empresas para as quais eles trabalham (as estatais dos mais diversos ramos produtivos) estavam encolhendo, o setor que empregava o crescente número de trabalhadores migrantes crescia de forma sistemática, tanto nas grandes cidades, concentrado em torno das empresas com investimento privado, quanto no campo, nas TVEs.

No final da década de 1990, Liaoning era a província com o mais severo índice de desemprego na China. Berço da industrialização pesada no período maoísta, a província sofreu um esvaziamento produtivo, com a transferência dos investimentos estatais e privados para o sul e a privatização de um enorme número de empresas estatais, a base produtiva local. Segundo estimativas da mesma época, entre 30\% e 60\% dos trabalhadores do setor estatal da província estavam desempregados, cálculos locais apontavam a taxa de $60 \%$ (Liang, 2001). O número de trabalhadores empregados no setor de 
manufatura da província caiu de 4,618 milhões em 1990 para 1,447 milhão em 2004, ou seja, para menos de um terço em cerca de 15 anos. Uma pesquisa feita em 1997 na província mostrou que $41 \%$ dos trabalhadores desempregados tinham mais de um ou dois membros da família na mesma situação (Lee, 2007).

Em 2000, uma pesquisa realizada pela Academia Chinesa de Ciências Sociais, citada por Solinger (2001), estimou que havia cerca de 27 milhões de chineses demitidos de empresas estatais, o que representava cerca de um quarto do total de funcionários de empresas estatais do país ${ }^{5}$. A taxa de desemprego da China é mais alta entre os estudantes graduados recém-formados e trabalhadores de meia idade demitidos pelas empresas estatais ao longo do processo de privatização. Em geral, as fábricas recéminstaladas ou privadas preferem os trabalhadores migrantes e mais jovens em suas linhas de produção.

Com a crise de 2007 a situação se agravaria, em particular junto aos migrantes, que foram os mais atingidos pelo fechamento de diversas fábricas nas Zonas Econômicas Especiais. No caso dos trabalhadores migrantes demitidos, a solução, em geral, é o retorno ao campo, esperando que os antigos postos de trabalho sejam reabertos nas cidades ou que apareçam novos.

Nos primeiros meses de 2009 a taxa de desemprego oficial chinesa, considerandose apenas a população com hukou urbano, era de 4,2\% a 4,3\%, uma taxa que é chamada pelo governo chinês de taxa oficial de desemprego urbano registrado ${ }^{6}$ - o que não reflete o expressivo incremento na taxa de desemprego no país provocada pela crise internacional. Esta atingiu de forma mais significativa os trabalhadores migrantes, os mais vulneráveis dentre os trabalhadores chineses e mais sujeitos às flutuações no comércio internacional.

\section{b. A SEGUNDA GERAÇÃO DE MIGRANTES}

Recentemente, além da atuação coletiva dos trabalhadores e das mobilizações, as empresas têm se deparado com uma nova realidade no que se refere ao comportamento e ao perfil dos trabalhadores migrantes. A chamada segunda geração de trabalhadores migrantes, nascidos depois de 1980, é muito diferente daqueles migrantes que foram trabalhar nas empresas de investimento externo e novas empresas privadas logo nos primeiros anos de adoção da política de reforma e abertura no início da década de 1980.

\footnotetext{
${ }^{5}$ Segundo a mesma pesquisa, os dados de trabalhadores demitidos por ano são: 3 milhões, em 1993; 3,6 milhões, em 1994; 5,6 milhões, em 1995; 8,91 milhões, em 1996; 11,51 milhões, em 1997; 8,9 milhões, em 1998; e 9 milhões, em 1999.

${ }^{6} \mathrm{O}$ registrado diz respeito ao hukou.
} 
A chamada primeira geração de trabalhadores migrantes chegava disposta a aceitar qualquer trabalho nas cidades. Saía do campo deixando o trabalho nas lavouras e esperava juntar algum dinheiro para enviar à família que deixava para trás e levar de volta, quando retornasse, especialmente para se estabelecer nos vilarejos. As famílias ajudavam a arranjar seus casamentos com pessoas da mesma região e de um modo geral eles não tinham qualquer expectativa de permanecer nas cidades por mais do que cinco ou seis anos (ainda que muitos tenham permanecido). Os salários recebidos eram tremendamente baixos e os direitos trabalhistas constituíam uma realidade distante e, muitas vezes, desconhecida. Eram homens com, em média, mais de vinte dois anos (Solinger, 1999; Chan e Buckinham, 2008; Ngai 2005, 2007).

Essa segunda geração muitas vezes não conta com as concessões para o uso da terra que seus pais receberam para trabalhar no campo; normalmente não chegaram a trabalhar na agricultura e, embora alguns deles tenham nascido nas cidades, filhos da primeira geração de migrantes, muitos ainda têm o hukou rural, já que o registro dos filhos é fixado segundo o dos pais. Em 1998, o governo central chinês promoveu uma mudança importante na atribuição de registros de hukou das crianças que nasciam no país. A partir daquele ano, as crianças podiam ser registradas segundo o hukou do pai e da mãe. Até então, as crianças eram registradas sempre segundo hukou materno. Mesmo quando nascidas nas cidades, essas crianças passavam parte de sua vida no campo com familiares, pois só poderiam frequentar as escolas no local de seus registros de residência.

Eles são parte da geração dos chamados príncipes chineses, como são chamados os filhos únicos, frutos da política de mesmo nome, e são mais conscientes dos riscos trazidos pelo trabalho nas fábricas e à sua saúde pelas condições de trabalho que encontram. Conhecem a experiência de seus antecessores em primeira mão, cresceram ouvindo como era a vida de seus pais, tios e tias, quando estiveram nas cidades e que posteriormente fizeram o caminho de volta ao longo das duas primeiras décadas de abertura econômica.

Sua referência de padrão de vida não é a vida no campo, como era o caso dos trabalhadores da primeira geração. Seus parâmetros são as condições de vida nas grandes cidades para onde migram e normalmente não buscam um emprego em caráter temporário. Diferentemente de seus pais, muitos deles querem se estabelecer nas cidades, tentam estudar e querem ter algum tipo de carreira, ainda que, por migrarem mais jovens que seus antecessores, acabem por abandonar os estudos mais cedo, resultando em baixo grau de escolaridade média entre esses trabalhadores. Como declarou um advogado que lidava com causas de trabalhadores de migrantes em Guangdong, os trabalhadores mais jovens entendem melhor o que significa ter um emprego e querem um que ofereça melhores condições, menos horas extras e um salário mais alto; querem ficar nas cidades, mas sair da linha de produção, não permanecer lá por toda a vida (Harney, 2009). 
Em geral, esses jovens, na melhor das hipóteses, saem do ensino médio no campo e vão para as cidades em busca de trabalho, muitas vezes sem sequer passar pelo trabalho no campo e não querem ser identificados como camponeses ${ }^{7}$. Além disso, já têm parentes ou amigos que migraram antes deles e que podem ajudá-los a encontrar trabalho, um lugar para ficar, ou podem conseguir algum dinheiro emprestado para os primeiros tempos na nova cidade.

O conhecimento desses chineses sobre a legislação trabalhista também é muito maior. Muitos evitam as fábricas, que exigem muitas horas extras de trabalho ou são conhecidas por uma rotina de trabalho mais dura. Por isso, a rotatividade deles entre as indústrias chinesas é muito grande, bastante maior que a de seus antecessores. Mesmo tendo que abandonar parte dos salários, que as empresas seguram como forma de tentar evitar o abandono de emprego, eles deixam as fábricas quando podem, em busca de melhores condições de trabalho. $\mathrm{O}$ uso da força pelas fábricas para mantê-los cresceu também em função desta mudança de comportamento. Assim como seus predecessores, eles enviam dinheiro para suas famílias no campo, mas tendem a manter uma parcela maior de seus salários para os próprios gastos. Eles procuram passar mais tempo nas cidades, melhorar seu padrão de vida tão logo têm chance, e buscam formas de fixar residência nos locais para onde migram.

Han Dongfeng, fundador do China Labour Bulletin, uma organização não governamental que lida com as violações aos direitos dos trabalhadores na China, e um dos líderes dos protestos na praça Tiananmen em 1989, declarou em 2005 que uma das razões para que a segunda geração de trabalhadores migrantes esteja mais atenta e lute mais por seus direitos é que não há outra escolha (Han, 2005). A redução do volume de terras aráveis disponíveis no interior da China significa que os trabalhadores migrantes têm pouco ou nada para o que retornar. "Eles não têm para onde ir. Essa é a realidade" (Harney, 2009, p. 122). As dificuldades e a crescente diferença de renda entre o campo chinês e as cidades, além da falta de terras para trabalhar e sustentar suas famílias, produziram um fenômeno de expulsão desses jovens, fazendo com que eles deixem suas terras natais e façam tudo o que podem para ficar nas cidades.

Outra distinção entre a segunda e a primeira geração de migrantes é fruto do próprio crescimento econômico chinês. Agora, além de Guangdong, há outras regiões atraindo migrantes, como o delta do Yangtze (cujo centro econômico é Shanghai), as províncias de Fujian e Zhejiang, grandes cidades como Beijing e Tianjin no norte e as capitais provinciais de um modo geral. Com o aumento do grau de exigência dos trabalhadores, as fábricas passaram inclusive a instalar infraestrutura de lazer para seus empregados (Ngai, 2007).

\footnotetext{
${ }^{7}$ Eles procuram se adaptar e apagar as características camponesas de todas as formas possíveis, desde os esforços para falar mandarim mais parecido com o padrão (de Beijing), até roupas, comportamento, etc.
} 
Segundo Harney (2009), o gerente de uma fábrica em Shenzhen disse que dez anos antes os trabalhadores perguntavam se a fábrica operava com horas extras e se a resposta fosse positiva eles queriam o emprego. Hoje os trabalhadores fazem a mesma pergunta e, se a resposta é positiva, perguntam sobre a quantidade de horas e muitas vezes não aceitam o emprego. Mesmo tendo concedido aumentos de 37\% em 2008 a fábrica continuava perdendo trabalhadores, porque a linha de produção não tinha aparelho condicionador de ar. Reclamações sobre a comida e as instalações das fábricas têm se tornado cada vez mais comuns (Harney, 2009).

\section{c. FLEXIBILIZANDO: O SISTEMA DE PONTOS}

Outro elemento importante no que se refere às diferenças regionais diz respeito às políticas de flexibilização do hukou. O sistema de registro de residência impõe uma série de limitações à vida dos trabalhadores migrantes nas grandes cidades chinesas. Recentemente, diversas cidades adotaram medidas para estimular e/ou facilitar a transferência dos registros de residência, como iniciativa dos governos locais que busca "legalizar" a situação dos trabalhadores locais e fixar parte deles nas cidades onde vivem.

A municipalidade de Chongqing, no centro da China, iniciou uma reforma no sistema de registro de residência que busca converter 10 milhões de camponeses em cidadãos urbanos até 2020. Chongqing contava com uma população de mais 28 milhões de pessoas em 2008; destes, 49,9\% eram moradores com hukou urbano e 50,1\% moradores com hukou rural. Isso significa que a municipalidade pretende converter o hukou de cerca de dois terços de seus moradores com hukou rural e mais de um terço de sua população total (National Bureau of Statistics of China, 2010). O governo municipal declarou em 2010 que tornaria 3,38 milhões de trabalhadores migrantes, nascidos entre 1980 e a década de 1990, moradores urbanos dentro de dois anos.

Segundo os novos regulamentos, aqueles que possuem negócios na área central da cidade há mais de cinco anos ou em áreas mais remotas por mais de três anos poderiam requerer o registro urbano. Além disso, eles poderiam fazer a conversão do hukou sem abrir mão de seus direitos sobre a terra ou sobre a terra contratada por três anos depois de se tornarem moradores urbanos. A possibilidade de manter, ainda que temporariamente, o direito sobre a terra torna a possibilidade de conversão do hukou muito mais interessante para os camponeses. Muitos deles sequer requerem a mudança do registro por temor de que suas famílias tenham que abrir mão da parcela de terra que lhes cabe e continua sendo cultivada pelos parentes que permaneceram no campo.

A capital provincial de Sichuan, Chengdu, promulgou uma lei que acabava com hukou em novembro de 2010. Segundo o Global Times (2010), o comunicado foi feito 
pelo governo da cidade no dia 16 de novembro de 2011, com a promulgação de uma lei que libera totalmente o movimento de camponeses e lhes concede os mesmos diretos desfrutados pelos moradores urbanos da cidade. A nova lei entrará em vigor no final de 2012, quando o sistema de registro terá apenas o local de residência. Os sistemas de empregos, seguridade social e educação também serão unificados, assegurando os mesmo direitos a todos (Global Times, 2010).

A província de Guangdong, que tem mais de 31 milhões de trabalhadores migrantes, segundo os dados oficiais (certamente subestimados), lançou um programa para concessão da condição de morador urbano para os migrantes em 2010. A província planeja tornar 1,8 milhão de trabalhadores com hukou rural, moradores com hukou urbano até 2012. O projeto busca acelerar a "construção urbana da província beneficiando trabalhadores agricultores, juntamente com moradores urbanos pelo crescimento econômico da província, construindo cidades harmoniosas", segundo declaração da vicediretora do Departamento de Recursos Humanos e Seguridade Social de Guangdong, Lin Wangping, dada ao jornal oficial chinês, China Daily em 2010.

O programa que entrou em vigor em junho de 2010 quer conceder hukou urbano aos migrantes com nível educacional elevado, que cumpram as políticas de planejamento familiar e se atenham às políticas de Estado. Pessoas com antecedentes criminais não poderão contar pontos segundo o sistema de Guangdong. Apesar da declaração dada ao jornal também afirmar que os requisitos acima não são os únicos para obtenção do novo registro, fica claro que a política busca beneficiar migrantes com um perfil bastante específico e que representam um microcosmo dentro do universo da população migrante da província, composto por trabalhadores dos ramos industriais com escolaridade baixa, na sua maioria. A cidade de Guanzghou, capital da província, tinha criado um sistema de pontos para a requisição do hukou urbano no início da década de 2000.

Em 2009, Shanghai seguiu o exemplo e estabeleceu um sistema semelhante para a conversão do hukou. Segundo o sistema, de acordo com o grau de escolaridade, tempo de residência na cidade, registro de residência do cônjuge, renda e empregador, os moradores com hukou rural podem solicitar a conversão para hukou urbano. Sob o sistema, a cada item é atribuída uma pontuação que varia entre as duas cidades, e se o morador atingir uma pontuação mínima ele pode requerer a conversão. Teoricamente é um processo mais rápido e descomplicado que o antigo nonzhuangfei, que significa literalmente conversão de rural para urbano e estabelecia os mecanismos para a conversão. Porém, o fato é que muitos moradores se queixam das dificuldades para se atingir a pontuação requerida para conversão, além de temerem que o requerimento de contagem dos pontos os "torne" marcados pelos governos locais como moradores em situação ilegal. Além disso, a iniciativa é vista por muitos como uma manobra política para reduzir 
a pressão exercida pelo crescente contingente de moradores nessas cidades sem registro local, sem, no entanto, efetivar a conversão.

No caso de Beijing, não houve qualquer alteração significativa. Segundo estimativas, a população da cidade aumentou aproximadamente 500.000 pessoas por ano na última década, segundo o vice-diretor da Comissão de Desenvolvimento e Reforma de Beijing, Zhao Lai. Zhao também assegurou ao China Daily (2010), que Beijing melhoraria sua administração da população e manteria os termos atuais do sistema de registro de residência, sob pena de uma explosão populacional.

De um modo geral, as iniciativas de flexibilização do hukou e de mudanças no sistema de registro são regionais. O governo central mantém inalteradas as normas vigentes e, apesar de ter pautado a questão do sistema de registro de residência na reunião da Assembleia Popular Nacional pelo menos nos últimos dois anos, não há, no horizonte, qualquer perspectiva de efetiva mudança no sistema nacional. No caso das grandes municipalidades, onde a renda é mais elevada, a flexibilização caminha a passos mais lentos, dada a pressão maior exercida pelos fluxos migratórios. No caso das províncias centrais, cuja renda é mais baixa e cujas cidades têm se tornado receptoras de migrantes cada vez mais importantes, há sinais de flexibilização, tendo Chengdu como caso paradigmático.

\section{A CRISE DE 2007}

A crise financeira que começou em 2007 gerou um grande baque na economia mundial que não dá sinais de que se reverterá facilmente. Apesar das economias capitalistas mais avançadas ainda estarem lidando com os efeitos da crise, alguns países como a China parecem ter "sobrevivido" a ela, ou pelo menos terem resistido mais facilmente. Para muitos, isso é fruto da capacidade do Estado chinês de lidar com reveses como esse e da sua intensa intervenção na economia. Essa, no entanto, não parece ser uma boa explicação.

O processo de transformação da China no "chão de fábrica do mundo" e sua posição na divisão internacional do trabalho, combinada com a herança (do esforço de transição) socialista de reforma agrária, criaram condições distintivas para o capital internacional que aporta no país, como uma força de trabalho migrante com preço e características que potencializam sobremaneira a extração de mais-valor, tanto no que se refere aos custos de produção relacionados ao trabalho, que assume formas distintas no caso chinês, reduzindo as pressões sobre os salários, quanto na rápida desmobilização dos enormes contingentes de trabalhadores desempregados produzida pela crise. Parte significativa deles, não vendo outra alternativa, embarcou quase imediatamente nos trens rumo ao interior do país, para trabalhar no campo e no pedaço de terra de que dispunham. Segundo Chan (2010), um levantamento que cobriu oito províncias exportadoras de migrantes, apurou que cerca 
de seis milhões de trabalhadores tinham retornado até dezembro de 2008. Muitos deles estavam com todos os seus pertences, o que indica que a expectativa deles era de que não teriam chance de retornar à cidade depois do Festival da Primavera ${ }^{8}$.

Em 2009, o número de trabalhadores migrantes desempregados ultrapassou 20 milhões, o que representava $40 \%$ do desemprego total no mundo gerado pela crise global (Agência de Notícias Xinhua, 02/07/2010). De acordo com Chan (2010), isso fez com que as condições de trabalho dos migrantes no país piorassem ainda mais e as violações aos direitos desses trabalhadores se ampliassem. Funcionários do Departamento Nacional de Estatísticas declararam que os trabalhadores migrantes chineses foram os mais severamente atingidos pela crise. Somado ao fato de que esses trabalhadores não contam com qualquer tipo de alternativa ou sistema de seguridade social, isso torna o retorno ao campo sua primeira opção, dado que eles são ainda mais vulneráveis às oscilações econômicas provocadas pela crise.

Pressionada pelo aumento nos preços de diversas matérias primas, pelos aumentos salariais gerados pela resistência direta dos trabalhadores e pela nova legislação trabalhista chinesa assim como pela valorização do Renminbi e a queda da demanda dos Estados Unidos e União Europeia provocadas pela crise (com queda abrupta da demanda internacional), a indústria chinesa viveu uma mudança abrupta. A taxa de crescimento do produto interno bruto da província de Guangdong, que estava entre aquelas que tinham as maiores taxas do país desde o início da década de 1980, sofreu uma expressiva queda com a crise. Tanto em 2008 quanto em 2009, a província ficou em último lugar na lista de 17 províncias cujas taxas de crescimento são calculadas (Chan, 2010). Cerca de 62.000 fábricas fecharam apenas em Guangdong durante o ano de 2008, e a crise não atingiu apenas as províncias orientadas às exportações. Pequenas fábricas em províncias como Hunan, cujo proprietário entrevistado por Harney (2009) previra uma queda significativa em sua competitividade em três ou cinco anos, fecharam em menos de 18 meses. Os preços subiram nas fábricas remanescentes; algumas registraram incrementos em seus preços de até $50 \%$.

Um dos efeitos da crise é o movimento de interiorização das empresas na China para lidar com as crescentes pressões exercidas pelos custos. A Foxconn ${ }^{9}$ pretende instalar uma nova planta em Hunan, com diversos benefícios fiscais (concedidos pelo governo provincial) e a expectativa de contar com uma pressão menor por aumentos salariais. À migração intraprovincial e às facilidades com algumas das políticas de flexibilização

\footnotetext{
${ }^{8}$ Ano novo lunar chinês e principal feriado do país, quando os migrantes costumam retornar às suas vilas de origem para passar algum tempo com as famílias.

${ }^{9}$ Gigante do setor de equipamentos eletrônicos, oriunda de Taiwan, que possui gigantescas plantas na China continental.
} 
do hukou, somam-se os baixos salários como fatores importantes para a atração das empresas para o centro da China. Mesmo os salários mínimos são menores nessas províncias. Segundo o departamento de comércio de Hunan (Agência de Notícias Xinhua, 13/01/2011), trabalhadores industriais da linha de produção recebem, na província, pouco mais de 1.000 yuans por mês para 60 horas de trabalho semanais, e a fiscalização sobre os direitos desses trabalhadores é praticamente inexistente.

Excluindo os trabalhadores migrantes que estão em TVEs e nas imediações de suas regiões de origem, os trabalhadores migrantes chineses totalizavam 150 milhões em meados de 2008. Cerca de metade destes trabalhadores retornaram ao campo durante o Festival da Primavera de 2009, um incremento significativo, já que a média de retorno era de $40 \%$ nos anos anteriores. Segundo as mesmas estimativas esse aumento no fluxo foi provocado pelo desemprego nas cidades exportadoras chinesas. Os setores que mais "enviaram" trabalhadores para casa foram a manufatura, com 36\%, e a construção civil, com $28 \%$, o que reforça a constatação sobre a grande participação dos trabalhadores migrantes nestes setores feita anteriormente.

Dos trabalhadores migrantes que retornaram ao campo chinês, $80 \%$ fizeram o caminho de volta às cidades após o feriado. A maioria conseguiu encontrar empregos, mas, um mês depois do retorno, 20\% deles continuavam desempregados. Dentre os que permaneceram no campo, apenas dois milhões dos cerca de 14 milhões foram absorvidos em atividades rurais.

O cálculo da taxa de desemprego entre os migrantes é problemático; porém, assumindo que $50 \%$ de trabalhadores migrantes que não retornaram ao campo durante o feriado do Festival da Primavera continuavam em seus empregos, estima-se que o desemprego tenha sido, em 2009, de 23 milhões de trabalhadores migrantes, cerca de 16,4\% - uma taxa muito elevada, se comparada com os anos anteriores. A taxa histórica de desemprego entre os trabalhadores migrantes chineses era baixa, oscilando entre $1 \%$ e $2 \%$.

A crise inverteu a relação das taxas de desemprego entre os chineses com hukou urbano e rural. A taxa dos detentores de hukou urbano ficou estável e não foi muito diferente daquela dos anos anteriores a 2009, registrando 4,3\%, em contraste com a significativa alta entre os detentores de hukou rural migrados nas cidades chinesas, considerando-se o primeiro semestre do ano.

No segundo semestre a economia chinesa deu sinais de recuperação, com o auxílio de diversas iniciativas do governo. Um delas foi a adoção de um grande pacote de estímulo ao consumo que, combinado com o aumento da demanda por produtos chineses provocada pelas encomendas de natal no ocidente, começou a dar resultados. Além disso, o governo chinês lançou uma política de estímulo ao retorno ao campo e início de novos negócios nos vilarejos natais dos migrantes retornados. Outras políticas também foram adotadas, como assistência aos exportadores, com descontos maiores nos 
impostos, linhas de créditos com taxas de juros baixas oferecidas pelos bancos estatais e financiamento para propagandas das empresas em outros países. Essas políticas combinadas ajudaram a arrefecer a alta taxa de desemprego em 2009, mas os benefícios foram absorvidos majoritariamente por empresas de investimento estrangeiro, que tiveram prioridade no acesso a diversos deles, reforçado o processo de concentração por parte das grandes empresas em detrimento das pequenas.

O pacote de estímulo ao consumo interno, apesar de não ter conseguido reverter completamente as perdas na produção e no emprego geradas pela redução na demanda externa, tiveram importante papel na retomada das operações de parte das empresas que fecharam logo no início da crise. O consumo tem crescido na China: em 2010 a taxa de crescimento em relação a 2009 no primeiro semestre foi de 18,2\%, atingindo 6,03 trilhões de yuans (Agência de Notícias Xinhua, 02/07/2010).

Os investimentos externos também registraram significativos incrementos, com taxa de crescimento de 20,65\% nos primeiro semestre de 2010 , segundo declaração do governo chinês, estimulados pela incerteza gerada pela crise sobre a capacidade de reação da economia de outros países, o que potencializou a posição chinesa. Nesse mesmo período, a China registrou o estabelecimento de 14.459 companhias de investimentos estrangeiro no país, $17 \%$ de crescimento em relação ao mesmo período do ano anterior, segundo a Agência de Notícias Xinhua (02/07/2010).

O retorno dos migrantes ao campo chinês era problemático em diversos sentidos. O primeiro deles era a falta de experiência ou de conhecimento sobre o trabalho na agricultura. A maioria dos retornados era de trabalhadores da segunda geração de migrantes, que foram mais jovens para as cidades e não tinham experiência com a rotina agrícola. Até por esse motivo, eles não tinham acesso fácil à parcela de terra destinada a eles, já que muitos a deixaram abandonada (quando a família não tem condições de ocupá-la) ou a sublocaram. O mais dramático era que, mesmo assegurado o acesso à terra e conseguindo trabalhar nela, garantir o sustento com o trabalho agrícola em uma porção de terra pequena e muitas vezes sujeita a outros tipos de dificuldades - a falta de água e de insumos agrícolas era o mais comum - por conta da baixa renda e da falta de terras aráveis, era muito improvável e era, afinal, uma das principais razões pela qual muitos deles tinham deixado o campo.

A campanha lançada pelo governo para estimular o retorno ao campo se chamava "retornar ao vilarejo para construir o interior". Ela buscava estimular a geração de renda no campo. Nos meses que se seguiram, mais trabalhadores retornaram às cidades; ainda assim, a retomada da operação das fábricas em Guangdong e outras províncias, posterior à crise, não atingiu seu nível imediatamente anterior. Mas os fluxos foram retomados e parte desses trabalhadores acabou conseguindo reencontrar empregos nas cidades, ainda que as taxas de desemprego entre eles ainda sejam elevadas. 
O impacto sobre os trabalhadores migrantes da crise que ainda atinge o mundo é uma das evidências de sua importância no setor mais dinâmico da economia chinesa. $\mathrm{O}$ intenso crescimento industrial do país requereu e ainda requer que esses enormes contingentes de trabalhadores deixem o campo sob condições (a posse da terra, os baixos salários, etc.) que são parte importante da explicação do fenômeno chinês. As novas relações de trabalho que essas condições criaram e as transformações que elas têm sofrido recentemente são fundamentais para compreender a competitividade chinesa na atualidade e mostram como as peculiaridades do gigante asiático podem pesar na sua estrutura de custos e na opção de empresas do mundo inteiro que se instalaram e continuam se instalando no país.

\section{REFERÊNCIAS}

AGÊNCIA DE NOTÍCIAS XINHUA. China obriga empregadores a assinar contratos de trabalho. Beijing, 13 jan. 2011.

AGÊNCIA DE NOTÍCIAS XINHUA. Foxconn terá bases de produção e pesquisa no interior da China. Beijing, 09 dez. 2010.

AGÊNCIA DE NOTÍCIAS XINHUA China retoma taxa de crescimento de dois dígitos. Beijing, 02 jul.

AGÊNCIA DE NOTÍCIAS XINHUA. Diferença entre a renda urbana e rural na China está maior apesar da recuperação econômica. Beijing, 22 jan. 2010.

CHAN, K. W. The Household Registration System and Migrant Labour in China: Notes on a Debate. Population and Development Review, v. 36, n. 2, p. 357-364, June, 2010. Disponível em: http://faculty.washington.edu/kwchan/Chan-hukou.pdf. Acesso em: 22 ago. 2012.

CHAN, K. W.; BUCKINHAM, W. Is China Abolishing the Hukou System? The China Quarterly, n. 195, p. 582-606, 2008.

CHINA DAILY. Administração de trabalhadores migrantes em Beijing aponta a importância da administração da população. Beijing, 06 out. 2010.

CHINESE ACADEMY OF SOCIAL SCIENCES (CASS). The Urban Blue Book: China City Development Report No. 5. Beijing: Chinese Academy of Social Sciences, 2012.

GAO, Y. China as the Workshop of the World. New York: Taylor \& Francis, 2011.

GLOBAL TIMES. Chengdu reforms Hukou System. Beijing, 10 nov. 2010.

HARNEY, A. The China price, the true cost of Chinese competitive advantage. New York: Penguin Books, 2009.

LEE, C. K. Against the Law. Labour protests in China's rustbelt and sunbelt. Berkley: University of California Press, 2007.

LIANG, Z. The Age of Migration. Population and Development Review, v. 27, n. 3, p. 499-524, September, 2001. 
NATIONAL BUREAU OF STATISTICS OF CHINA. China Statistical Yearbook 2010. Beijing: China Statistics Press, National Bureau of Statistics, 2010. Disponível em: <http://www.stats. gov.cn/english/statisticaldata/yearlydata/>. Acesso em: 19 maio 2011.

NGAI, P. Gendering the dormitory labour system: production, reproduction and migrant labour in south China. Feminist Economics, v. 13, n. 3-4, July/October, p. 239-258, 2007.

NGAI, P. Made in China, women factory workers in a global workplace. Durham: Duke University Press, 2005.

SOLINGER, D. Contesting citizen in urban China: peasant migrants, the state and the logic of market. Berkley: University of California Press, 1999.

SOLINGER, D. Why we cannot count the "unemployed". The China Quarterly, v. 167, September, p. 671-68, 2001.

TANG, W.; YANG, Q. The Chinese Caste Urban System in Transition. The China Quarterly, v. 196, p. 759-779, December, 2008.

XIN, M. Labour Market Reform in China. Cambridge: Cambridge University Press, 2004. 